\title{
Oil Currency and the Dollar Standard: A Simple Analytical Model of an International Trade Currency*
}

\author{
Michael B. Devereux \\ University of British Columbia, CEPR, NBER \\ Kang Shi \\ Chinese University of Hong Kong \\ Juanyi $\mathrm{Xu}$ \\ Hong Kong University of Science and Technology
}

September 2009

\begin{abstract}
It is widely accepted that the US dollar is the central reference currency for international trade pricing in final goods. At the same time, the dollar is the main invoicing currency for primary commodities. This paper links these two observations within a stylized theoretical framework, and shows how this may be used to obtain a quantitative estimate of the gain to the US economy from the use of the US dollar as a reference currency. With dollar invoicing of primary commodities, US firms bear less exchange rate risk than foreign firms when facing primary commodity price shocks (even when commodity prices are fully flexible). As a result of this asymmetry, all firms in the world will set their export prices in US dollars. This implies a dollar standard in international goods pricing. The paper derives a simple analytical formula to calculate the gains to the representative US household from the dollar standard. We find that the gains are extremely small.
\end{abstract}

JEL classification: F3, F4

Keywords: oil currency; currency of export pricing; dollar standard; welfare gain

${ }^{*}$ Devereux thanks SSHRC, the Royal Bank, and the Bank of Canada for financial support. Xu thanks SSHRC and the SFU PRG grants for financial support. This research was also undertaken as part of University of British Columbia's TARGET research network. All authors thank TARGET for financial support. We thank two anonymous referees, Angela Redish, and seminar participants at UBC, the 2006 Annual Conference of the Canadian Economics Association, and 2009 Tsinghua Macro Workshop for helpful comments and suggestions. The views in this paper are those of the authors alone and not those of the Bank of Canada. E-mail: devm@interchange.ubc.ca, kangshi@cuhk.edu.hk, jennyxu@ust.hk 


\section{Introduction}

It is widely acknowledged that the US dollar is the central reference currency for international trade pricing. Goldberg and Tille (2008a) establish that the dollar is overwhelmingly used for invoicing both export and import prices for the US economy. This finding is complemented by Gopinath and Ribogon (2008), who note that there is a very low pass-through of exchange rate changes into US dollar prices of both export and imports in the US economy. Hence a good approximation is that prices of US imports and exports are set in US dollars. Countries exporting to the US set their prices in dollars, and countries importing from the US accept prices set in dollar terms. Moreover, even for non-US related exports Goldberg and Tille (2008a) note that a substantial component is invoiced in US dollars.

A second empirical characteristic of international trade pricing is that exports of primary commodities, including oil, are substantially invoiced in US dollars. As shown by Goldberg and Tille (2008a), dollar invoicing of commodities is a much more predominant phenomenon even than dollar invoicing of trade in non-primary commodities. Table 1 provides some additional evidence. Of 81 raw material price series published by the UNCTAD, only 5 are not dollar denominated. Similarly, in the construction of the Rogers International Commodities Index, only 5 out of 35 commodity contracts comprising the Index are not denominated in US dollars. The total weighting of these non-dollar denominated commodity in the Index is only $2.02 \%$. Similarly, Table 2 presents some stylized facts regarding US dollar invoicing in overall trade flows for selected countries. ${ }^{1}$

This paper links these two observations within a stylized theoretical framework by assuming that the primary commodity goods ('oil') is used an input for the production of the final goods, and shows how we may use this linkage to obtain a quantitative estimate of the gain to the US economy from the use of the US dollar as a reference currency. Our model is one in which the currency of export price invoicing of final goods is endogenous, and chosen by exporting firms themselves. Firms have to set final goods prices in advance, but may choose the currency in which they set goods prices. We show that the practice of US

\footnotetext{
${ }^{1}$ Interestingly, oil prices have been mostly quoted in US dollars since the first drilling in the US in the mid19th Century, even during the predominance of sterling as a world currency (Bamberg, 2000). As regards other commodity prices, the London Metal Exchange lead contracts were denominated in sterling until 1993, at which point trading switched to US dollars. Lead (with copper) was the last of the LME-traded metals to make the change.
} 
dollar pricing of export goods follows as a natural implication of dollar invoicing of primary commodities, both for US exporters and for foreign firms exporting to the US. Hence the convention of dollar invoicing of primary commodities leads naturally to the asymmetric pattern in the currency of price setting for trade in final goods. This holds true even if primary commodities represent only a small share in overall production.

Our model implies that the US consumer gains from the use of the dollar as an invoicing currency. The mechanism by which this occurs is through adjustment of national price levels. When export prices are invoiced in dollars, the US price level is lower than that of the rest of the world, controlling for the monetary rule in each region. Thus, expected (log) consumption in the US is higher than that of the rest of the world, ceteris paribus, and US consumers are better off.

How much better off are US consumers? Our model delivers a simple formula to calculate the magnitude of the welfare benefit that the US obtains from its position as a reference currency. We calibrate by choosing parameters for the relative size of the US economy, the share of primary commodity imports in production, and the volatility of fundamentals driving the exchange rate. We find that the gains to the representative US household are extremely small; at most 0.01 percent of steady state consumption.

Even these estimates depend on the stance of monetary policy. Our first estimate above assumes that monetary policy is determined arbitrarily. But if monetary policy is chosen optimally by each region so as to maximize expected utility in face of sticky nominal prices, then the welfare gains to the US are likely to be even smaller. The reason is that monetary policy is more effective, the higher is exchange rate pass-through. When pass-through into the US economy is limited, this constrains the ability to use monetary policies efficiently in the US relative to the rest of the world. We also find that there may exist multiple equilibria of the game between firms and monetary authorities.

The central message of the paper relies on drawing a connection between the two institutional features of US dollar invoicing of primary commodities and the asymmetric currency of price-setting of US exports and US imports. We take the first feature as exogenous to our model. At first glance, this might seem to be weakness in the analysis. But a key distinction to highlight is the difference between flexible price goods and sticky prices goods. The evidence clearly suggests that nominal prices of primary commodity exports are flexible. Typically, the standard deviation of primary commodity prices is substantially 
larger than that of bilateral exchange rates. On the other hand, final goods prices are an order of magnitude less variable than bilateral exchange rates. In our model, we assume that primary commodity prices are fully flexible, while final goods prices are sticky (set in advance). Thus, since primary commodity exporters (not modeled directly in our analysis), can adjust their price in response to changes in the exchange rate, it will not matter to them in what currency that invoicing of transactions is made. By contrast, for final goods producers, who have to pre-set the nominal goods price in the invoicing currency, the choice of invoicing currency will affect the distribution of realized profits.

The paper is based on the assumption that the price of oil is an exogenous stochastic process. This assumption is quite common in the literature (see the discussion of oil-based DSGE models below). While in principle, it would be appealing to have a full general equilibrium structure incorporating oil price determination (e.g. by formulating OPEC price decisions), as a first approximation, it may not be a poor assumption to take oil prices as determined separately from domestic decisions over prices and invoice currency. In a technical appendix, we show that allowing oil prices to co-vary with domestic monetary policy shocks does not significantly alter our results.

The paper builds on a number of previous contributions. A substantial group of empirical papers have noted the low degree of exchange rate pass-through into the US economy, both on the import and export side (Engel, 1999, Frankel, Parsley and Wei, 2005, Gopinath and Rigobon 2008, Goldberg and Tille, 2008a). Of course, there are a large number of alternative explanations of low pass-through. Our model focuses only on one dimension the role of sticky prices in local currency.

A related literature has discussed the predominant role of the US dollar as a reference currency in international trade. McKinnon (2001) defines this phenomenon as a 'Dollar Standard' (see also McKinnon, 2002, McKinnon and Schnabl 2004). More general discussion of the determinants of international currencies may be found in Portes and Rey (1998) and Hartmann (1998). As discussed above, our analysis is based on providing an explanation of this outcome as an endogenous configuration. To our knowledge, the connection between currency invoicing of primary commodities and the adoption of a reference currency in international trade pricing had not been made before. ${ }^{2}$

\footnotetext{
${ }^{2}$ After the first version of this paper was written (Devereux, Shi and Xu, 2005a), our attention was drawn to an interesting complementary paper by Novy (2006). Novy develops a three country model of
} 
The theoretical model in the paper relies on a recent literature analyzing the factors which determine the choice of exporting currency for a price-setting firm. On the one hand, partial equilibrium models by Giovaninni (1988), Friberg (1998), and Bachetta and Van Wincoop (2005) emphasize the importance of the elasticity of demand and market share. Alternatively, Devereux, Engel, and Storgaard (2004) look at the same question within a general equilibrium framework, emphasizing the role of aggregate shocks. Our paper falls within the latter approach .

Finally, there are many papers that have incorporated the role of primary commodities, and in particular oil, into macroeconomic models. As in our paper, this literature mostly assumes exogenous oil price shocks (an exception is Elekdag et al, cited below). An important early contribution was Krugman (1983), which emphasizes the effect of an oil price increase on the US dollar exchange rates. ${ }^{3}$ More recently, Bodenstein et. al (2007), Elekdag et al. (2008), and Leduc and Sill (2007) have analyzed oil as an integral part of open economy DSGE models. They emphasize the role of oil in production in ways quite similar to the approach we use below. That is, oil is treated as a direct input in the production process. It is combined with capital and/or labor to produce output goods, and the elasticity of substitution between oil and other factors is constant. In contrast to our paper, these papers are particularly concerned with the quantitative business cycle implications of the oil market. The production specification and dynamic aspects of these models are therefore richer than in the present paper.

The paper is also part of a more general literature on 'vehicle currencies' in international trade and capital markets. The term 'vehicle currency' applies to any situation where either the price or the currency of exchange in a transaction between one country and another is set in the currency of a third currency. Goldberg and Tille (2008a) document the widespread use of the dollar as a vehicle currency in trade invoicing. But the use of a vehicle currency is also important in facilitating exchange. For instance, BIS reports that the US dollar

endogenous invoicing, and shows the importance of inputs for the choice of currency of invoicing, focusing, among other issues, on the possibility for 'vehicle currencies' (see below) in invoicing to arise. Our initial results on the role of oil as an input is similar to that of Novy. Our paper differs in that we explore the welfare consequences of the invoicing decision, the implications for optimal monetary policy, and provide a quantitative assessment of the gains to the country from having an international currency.

${ }^{3}$ Krugman (1983) shows that the direction of this effect depends on a comparison of the direct balance of payments burden of the higher oil price with the indirect balance of payments benefits of OPEC spending and investment. 
is on one side of about 90 percent of global international currency exchanges. Thus, the dollar is a vehicle currency in global currency markets. The role of a vehicle currency along this dimension has been explored by Krugman (1980), Rey (2001), and Devereux and Shi (2008). From an empirical perspective, the first definition of a vehicle currency should have implications for observations on trade invoicing, and the impact of exchange rate changes on import prices. In terms of the exchange facilitating role of a vehicle currency, the important implications should be seen in terms of currency holdings, the currency of settlement in transactions, and the currency composition of official foreign exchange rate reserves.

This paper is organized as follows. Section 2 presents the benchmark model. Section 3 solves the model and shows that a dollar standard is the equilibrium of firms' choices. Section 4 extends the benchmark model to include active monetary polices. Section 5 concludes.

\section{Basic Model}

The world economy consists of two countries; the home country (the United States) and the foreign country. There is a continuum of home goods (and home population) and foreign goods (foreign population) of measures $n$ and $1-n$ respectively. Each good is produced by a monopolistic competitive firm using oil (or more generally, primary commodities) and labor. There are three stochastic shocks; country-specific monetary and productivity shocks, and a common oil price shock.

It is also assumed that there exists a full set of nominal state- contingent assets, so asset markets are complete. To simplify the analysis, we abstract from any dynamics by considering a single period model with uncertainty. Since asset markets are complete, this assumption is in fact innocuous. The results from the one period model with complete markets will extend directly to an infinite horizon model.

The structure of events within the period is as follows; Before the period begins, households trade in a full set of nominal state-contingent bonds. The trade in state-contingent nominal assets across countries will lead to a cross country risk-sharing rule (specified in Section 2.1). Then firms choose the currency in which they set their export goods prices, given the cross country risk-sharing rule, and taking into account the way in which they will 
set nominal prices, as well as the distribution of the stochastic shocks. Following this, but before the realization of shocks, firms set prices, depending on the state-contingent discount factors, and the demand and marginal cost conditions that they anticipate to hold. After the realization of stochastic shocks, households work and choose their optimal consumption baskets, production and consumption take place, and the exchange rate is determined.

The detailed structure of the home country is described below. The foreign country has an identical structure. Where appropriate, foreign variables are indicated with asterisk.

\subsection{Households}

The representative household in the home country maximizes expected utility, defined as:

$$
U=E\left(\frac{C^{1-\rho}}{1-\rho}+\chi \ln \frac{M}{P}-\eta L\right)
$$

where $C=\frac{C_{h}^{n} C_{f}^{1-n}}{n^{n}(1-n)^{1-n}}, C_{h}=\left[\int_{0}^{n} n^{-\frac{1}{\lambda}} C_{h}(i)^{\frac{\lambda-1}{\lambda}} d i\right]^{\frac{\lambda}{\lambda-1}}, \lambda>1$, and $\rho \geq 1$. Here $C$ is home aggregate consumption, comprised of home goods and foreign goods with weights of $n$ and $1-n$ respectively. $C_{h}$ is the home sub-aggregate consumption of a continuum of home goods indexed by $[0, n]$, with elasticity of substitution between individual home goods equal to $\lambda$. $\frac{M}{P}$ are real money balances, and $L$ represents labor effort. $\eta$ and $\chi$ are positive constant scale parameters. $E$ is the expectation operator defined across all possible states of nature. The specification of (2.1) allows us to derive a closed form solution of the model. These assumption are also used in Obstfeld and Rogoff (2000), Devereux and Engel (2003), and Devereux, Shi, and Xu (2007). From the consumption structure, we may derive the consumption-based price index,

$$
P=P_{h}^{n} P_{f}^{1-n}
$$

where $P_{h}$ and $P_{f}$ represent the prices for home goods and foreign goods in the home country, respectively. The equations for the foreign country are analogous, but with prices and quantities denoted by asterisks.

Home and foreign households can trade a full set of ex-ante nominal state-contingent bonds ex-ante. The household enters each period with initial money balances $M_{-1}$, obtains wage income, and receives the profit from ownership of home goods firms. It is also assumed that government repays any seignorage revenue to households through a lump sum transfer. 
So the budget constraint for the home households in the state $\nu$ can be written as:

$$
B(\nu) \leq W(\nu) L(\nu)+\Pi(\nu)+M_{-1}+T(\nu)-P(\nu) C(\nu)-M(\nu)
$$

Meanwhile, the following equation has to be satisfied:

$$
\sum_{\nu \in \Theta} \xi(\nu) B(\nu)=0
$$

where $B(\nu)$ and $\xi(\nu)$ are the purchases of state-contingent nominal bonds for home households and the price of the bonds in the state $\nu$, respectively. Here, $\Pi(\nu)$ is defined as total profits earned by the home household from ownership of home firms in state $\nu$, and $T(\nu)$ represents money transfers from the central bank in state $\nu$. Following recent literature (e.g. Devereux and Engel, 2003), we may show that the trade in state-contingent nominal assets across countries will lead to the following risk-sharing condition:

$$
\frac{C^{-\rho}}{P}=\Gamma \frac{C^{*-\rho}}{S P^{*}}
$$

where $S$ is the nominal exchange rate, defined as the price of foreign currency in terms of home currency, and $P^{*}=P_{h}^{* n} P_{f}^{* 1-n}$ is the foreign price level.

Equation (2.5) is an equilibrium risk-sharing condition. $\Gamma$ is the state-invariant weight. ${ }^{4}$ From the appendix to Devereux and Engel (2003), we may show that equilibrium in the ex-ante securities market implies that

$$
\Gamma=\frac{E C^{(1-\rho)}}{E C^{*(1-\rho)}} .
$$

In addition, the home household's optimization gives rise to the money demand function:

$$
M=\chi P C^{\rho}
$$

and the implicit labor supply schedule:

$$
W=\eta P C^{\rho} .
$$

Therefore, the nominal wage is proportional to money in circulation. Combining the money market equilibrium for the home and foreign countries with cross country risk-sharing condition (2.5), we can derive the exchange rate as:

$$
S=\Gamma \frac{M}{M^{*}} .
$$

\footnotetext{
${ }^{4} \Gamma$ represents the ratio of the Lagrange multiplier on the home household budget constraint to the Lagrange multiplier on the foreign households budget constraint.
} 


\subsection{Oil/Primary Commodity Market}

Following Mork and Hall (1980) and some recent literature (see, for example, Leduc and Sill 2007, Elekdag et al. 2008, and Bodenstein et. al 2007), we treat oil as a direct input in the production process. Assume that the oil supply is owned by a third party such as OPEC. Both home and foreign firms have to import oil from OPEC. The price of oil is determined exogenously in US dollars. ${ }^{5}$ Let the oil price be denoted $Q$ (in U.S. dollars) and assume it follows a log normal distribution.

$$
\ln Q=q, \quad q \sim N\left(0, \sigma_{q}\right)
$$

Foreign firms face an oil price $\frac{Q}{S}$, in terms of foreign currency.

\subsection{Production}

Each firm $i$ in our economy has the following production technology.

$$
Y(i)=A(\theta L(i))^{1-\alpha} O(i)^{\alpha}
$$

where $O$ represents the amount of oil used in production, $A=\frac{1}{\alpha^{\alpha}} \frac{1}{(1-\alpha)^{1-\alpha}}$ is a constant parameter, $\alpha<1 / 2$ is the share of oil (or more generally, primary commodities) in consumption (or GDP), and $\theta$ is a country-specific productivity shock in the home country, following a log normal distribution ${ }^{6}$.

$$
\theta=\exp (z), \quad z \sim N\left(0, \sigma_{z}^{2}\right)
$$

The country-specific shock $\theta^{*}$ in the foreign country is analogously distributed, and $\sigma_{z}^{2}=$ $\sigma_{z^{*}}^{2}$. Marginal costs for home and foreign firms in term of their own currencies, respectively, are

$$
\begin{gathered}
M C=\left(\frac{W}{\theta}\right)^{1-\alpha} Q^{\alpha} \\
M C^{*}=\left(\frac{W^{*}}{\theta^{*}}\right)^{1-\alpha}\left(\frac{Q}{S}\right)^{\alpha}
\end{gathered}
$$

\footnotetext{
${ }^{5}$ As noted in the introduction, we do not model the supply side of world oil market and the pricing behavior of OPEC explicitly in this paper. There is strong evidence that the oil price can reasonably be argued as exogenous during the period 1948-1972. See Hamilton (1983,1985).

${ }^{6}$ It does not matter for the results whether the technology shock is Hicks Neutral or Harrod Neutral (or labor augmenting). This approach is slightly easier notationally.
} 
Equations (2.13) and (2.14) imply that the oil price shock has a direct impact on the firm's production cost, but the firms are in an asymmetric position in that the foreign firm's marginal cost depends both on the world dollar oil price, as well as its bilateral exchange rate against the US dollar. This asymmetry in cost structure will affect the endogenous currency of pricing decision for both home and foreign firms.

\subsection{Monetary Shocks}

In the baseline model, neither home or foreign monetary authorities are active. The money shocks in each country just follow a log normal stochastic process.

$$
\begin{gathered}
M=\exp (u) \\
M^{*}=\exp \left(u^{*}\right)
\end{gathered}
$$

where the terms $u$ and $u^{*}$ represent uncontrollable disturbances to money supply. These could represent financial innovation shocks, or implementation errors for policy makers. We assume that $u \sim N\left(0, \sigma_{u}^{2}\right)$, and $u^{*} \sim N\left(0, \sigma_{u^{*}}^{2}\right)^{7}$, and $\sigma_{u}^{2}=\sigma_{u^{*}}^{2}$. We also assume that the three external shocks are independent, i.e., the covariance terms between $\left\{u, u^{*}, z, z^{*}, q\right\}$ are all zero.

\subsection{Endogenous Currency of Pricing}

When a firm sells abroad, it can set its export prices in its own currency (PCP) or in buyer's currency (LCP). Whatever currency it chooses, it must set the price before the state of the world is known. If firms could freely reset their price after shocks are realized, they would be indifferent to the currency in which they set their export prices. There would then be no reason for one currency to become a reference currency for international pricing. Moreover, if nominal prices were flexible, the invoicing currency for oil pricing would not be a concern for firms.

Each firm $i$ in the home country, selling a differentiated good to the foreign market, faces a CES demand curve,

$$
X\left(P_{h f}^{*}(i)\right)=\left(\frac{P_{h f}^{*}(i)}{P_{h f}^{*}}\right)^{-\lambda} \frac{P^{*}}{P_{h f}^{*}} C^{*}
$$

\footnotetext{
${ }^{7}$ The mean of log money supply has no impact on the result of our model, for simplicity we assume a simple money rule in which the mean of log money supply equals zero.
} 
where $P_{h f}^{*}(i)$ is the price the foreign consumer pays for home-produced goods $i . P_{h f}^{*}$ is the price index for all home goods purchased by the foreign consumer, and $P^{*}$ is the foreign country consumer price index. These prices are expressed in foreign currency. There is no loss of generality in expressing them in this way. If the home exporter $i$ follows LCP, then she will directly choose $P_{h f}^{*}(i)^{L c p}$ in advance. If on the other hand, she follows PCP, then she chooses $P_{h f}(i)^{P c p}$, and the price facing the foreign buyer will be $P_{h f}^{*}(i)=\frac{P_{h f}(i)^{P c p}}{S}$.

If the home firm $i$ sets its price in its own currency (the currency of producer, PCP), then expected discounted profits from selling to foreign consumers are

$$
E \Pi^{P c p}=E\left[d\left(P_{h f}^{P c p}(i)-M C\right)\left(\frac{P_{h f}^{P c p}(i)}{S P_{h f}^{*}}\right)^{-\lambda} \frac{P^{*}}{P_{h f}^{*}} C^{*}\right]
$$

where $d=\frac{1}{P C^{\rho}}$ is the marginal utility of home households, which is used as the stochastic discount factor for home firms. $M C$ is the marginal cost of home firms.

If the home firm $i$ sets its price in the foreign currency (the currency of buyer, LCP), then expected discounteds profits are

$$
E \Pi^{L c p}=E\left[d\left(S P_{h f}^{* L c p}(i)-M C\right)\left(\frac{P_{h f}^{* L c p}(i)}{P_{h f}^{*}}\right)^{-\lambda} \frac{P^{*}}{P_{h f}^{*}} C^{*}\right]
$$

The home firm will set its price in its own currency if the expected profit differential $\Omega$ is positive. Thus, it follows PCP whenever

$$
\Omega=E \Pi^{P c p}-E \Pi^{L c p}>0
$$

In Devereux, Engel, and Storgaard (2004), it is shown that the above optimal condition can be approximated as: ${ }^{8}$

$$
\frac{1}{2} \sigma_{s}^{2}-\operatorname{cov}(\ln (M C), s)>0
$$

The equivalent condition for the foreign firm to follow PCP is given by

$$
\frac{1}{2} \sigma_{s}^{2}+\operatorname{cov}\left(\ln \left(M C^{*}\right), s\right)>0
$$

\footnotetext{
${ }^{8}$ We denote $s$ here as the log exchange rate. As derived in Devereux, Engel, and Storgaard (2004), the intuition behind Equations (2.21) and (2.22) is as follows. With PCP (LCP) pricing, profits are convex (linear) in the exchange rate, so that exchange rate volatility makes PCP more attractive. But with PCP pricing, demand and marginal cost covary positively so long as $\operatorname{cov}(m c, s)>0$. This reduces expected profits, making LCP more attractive. This result also builds on the early contribution of Giovannini (1988).
} 
That is, if a firm chooses its export price optimally, then up to a second order approximation, its decision depends only on the variance of the (log) exchange rate and the covariance of exchange rate with marginal cost, and is independent of the variance of market demand, the financial market structure and the prices of all other firms. In our model, due to the complete asset market assumption, the exchange rate is fully determined by money supply shocks and will not be affected by the measure of firms choosing PCP or LCP. Thus, all firms in one country will choose the same pricing strategy.

\subsection{Equilibrium}

Given the stochastic processes $\left\{u, u^{*}, z, z^{*}, q\right\}$, a symmetric equilibrium is a collection of allocations $\left\{C, C^{*}, L, L^{*}, M, M^{*}, B(\nu), B^{*}(\nu)\right\}$, and price system $\left\{P, P^{*}, W, W^{*}, P_{h}\right.$, $\left.P_{f}, P_{h}^{*}, P_{f}^{*}, S, \xi(\nu), \Gamma\right\}$ such that

- Given the price system, $\left\{C, C^{*}, L, L^{*}, M, M^{*}, B(\nu), B^{*}(\nu)\right\}$ solve the consumer's optimality problem, subject to his budget constraint.

- $\left\{P_{h}, P_{f}, P_{h}^{*}, P_{f}^{*}\right\}$ solve the individual firm's optimal pricing problem.

- The strategy of currency of pricing for each firm is optimal.

- The labor, goods, and money markets clear.

\section{Model Solution}

To derive the solution to the baseline model, firstly, we have to find the optimal currency of pricing decision for the firms. Then given the optimal pricing policies, we solve for the endogenous variables contingent on the realizations of external shocks. Finally, we calculate the expected welfare for the home and foreign consumers.

\subsection{The Currency of Pricing}

From Appendix A, we can derive the expected profit differential for both home and foreign firms as follows:

$$
\Omega=\alpha \sigma_{u}^{2}>0, \quad \Omega^{*}=-\alpha \sigma_{u}^{2}<0
$$


This implies that all firms in the home country will choose PCP and all firms in the foreign country will choose LCP, and the home currency (US dollar) will be the reference currency for international goods pricing. Thus, we can state the following proposition.

Proposition 1 When $\sigma_{u}^{2}=\sigma_{u^{*}}^{2}$, all home and foreign firms will choose the home currency as the reference currency for international goods pricing. This represents a dollar standard in the world economy.

The proof is given in Appendix A. The intuition can be developed from conditions (2.21) and (2.22). As discussed in Footnote 7, exchange rate volatility makes PCP more attractive, while a positive (negative) covariance between the exchange rate and marginal cost reduces expected profit for the home (foreign) firm, making LCP more desirable. In our model, the variance of the exchange rate is the same for both home and foreign firms. The covariance between exchange rate and marginal cost, however, differs across countries and depends critically on the currency in which oil is invoiced. For home firms, since oil price is quoted in home currency (the US dollar), the covariance of marginal cost and the exchange rate is relatively small, tilting the benefits towards PCP pricing. For foreign firms, marginal costs are additionally sensitive to the exchange rate because oil is quoted in US dollars. As a result, the covariance between marginal costs and the exchange rate is negative, and dominates the direct effect of exchange rate variance on profits, so long as $\alpha>0$. So the foreign firm's optimal pricing policy is LCP. ${ }^{9}$

Another way to see the intuition of proposition 1 is based on a hedging argument. If marginal cost is independent of exchange rates then both firms would have higher expected profits under PCP, because profits are convex in the exchange rate under PCP, but linear in the exchange rate under LCP. But for the foreign firm, marginal cost is strongly negatively related to the exchange rate. Then under PCP, when the exchange rate falls (a depreciation of the foreign currency), demand for foreign goods are higher, but foreign marginal costs are also higher. So PCP pricing represents a poor hedging policy in the sense that periods of high sales are associated with high marginal cost, and vice versa, leading to lower expected

\footnotetext{
${ }^{9}$ From Proposition 1, we see that the existence of the dollar standard does not depend on the size of the share of oil (or primary commodities) in production. This is partly due to our assumption of constant returns to scale in labor and oil. The technical appendix shows that with decreasing returns to scale, a lower share of oil in production gives rise to other possible pricing equilibria. But the dollar standard continues to be an equilibrium.
} 
profits. By contrast, LCP pricing is preferable, because then demand for foreign goods is not directly moved by changes in exchange rates.

For simplicity, we have imposed the condition that $\sigma_{u}^{2}=\sigma_{u^{*}}^{2}$ in Proposition 1. However, we can show that all firms will want to set their export prices in the US dollar as long as $\frac{\sigma_{u}^{2}}{\sigma_{u^{*}}^{2}}<\frac{1}{1-2 \alpha} \cdot{ }^{10}$ This implies a dollar standard can even exist in the case where monetary policy in the foreign country is slightly more stable than that in the US, i.e. when $\frac{\sigma_{u}^{2}}{\sigma_{u^{*}}^{2}}>$ 1. Equivalently, this condition gives an upper bound equal to $\frac{1}{1-2 \alpha}$ for which monetary volatility in the home country can exceed that in the foreign country, but still maintain a dollar standard. The more the economies rely on oil, the more likely it is that there is a dollar standard.

\subsection{Model Solution}

Given the determination of the currency of export pricing, the model admits a simple solution. This is explained in detail in the Technical Appendix. First, we can solve for the pre-set nominal prices of home and foreign goods, based on the firms optimal pricing first-order conditions. Given that both home goods and imported foreign goods in the home market have prices preset in home currency, the home CPI is completely predetermined and independent of external shocks. But there is positive exchange rate pass-through into the foreign CPI. This is an important channel through which a dollar standard may affect the global economy.

Then, for given pre-set prices, we may solve for consumption and employment levels in each country. In fact, consumption may be explicitly derived as:

$$
\begin{aligned}
C & =\left[\frac{1}{\chi} \frac{M}{P_{h h}^{n} P_{f h}^{1-n}}\right]^{\frac{1}{\rho}} \\
C^{*} & =\left[\frac{1}{\chi} \frac{M^{n} M^{*(1-n)}}{P_{h f}^{n} P_{f f}^{* 1-n}}\right]^{\frac{1}{\rho}} .
\end{aligned}
$$

This implies that home country consumption is independent of the realization of the foreign country money supply. This follows directly from the fact that the home country CPI is predetermined. But with full exchange rate pass-through into imported goods prices, foreign country consumption is affected by the home country monetary shocks.

\footnotetext{
${ }^{10}$ As mentioned in Section 2.3, $\alpha$, the share of oil (or more generally, primary commodities) in consumption (or GDP), is assumed to be less than $1 / 2$.
} 


\subsection{Welfare Comparison}

We now compare the welfare of a representative household in the home country with that in the foreign country and check if the US household gains when a dollar standard exists. It is assumed that the welfare of the household can be measured as ${ }^{11}$

$$
E\left(\frac{C^{1-\rho}}{1-\rho}-\eta L\right)
$$

Expected utility of the household is a function of variances and covariance terms of log consumption and log exchange rate. Thus, given the solution to the consumption and the exchange rate, we may rewrite welfare in terms of the variance of external shocks. From properties of the pricing setting equations in home and foreign country, and the labor market clearing condition in the home country, as shown in the Technical Appendix, we can establish that

$$
E(L)=(1-\alpha)\left\{\frac{n}{\hat{\lambda} \eta} E\left(C^{1-\rho}\right)+\frac{1-n}{\hat{\lambda} \eta} E\left(C^{* 1-\rho}\right) \Gamma\right\}
$$

Combining (3.4) and (3.5), we may rewrite the expected utility of the home household as

$$
E(U)=\frac{\lambda-n(1-\alpha)(\lambda-1)(1-\rho)}{(1-\rho) \lambda} E\left(C^{1-\rho}\right)-\frac{(1-n)(1-\alpha)(\lambda-1)}{\lambda} \Gamma E\left(C^{* 1-\rho}\right)
$$

Since the log-normal distribution satisfies $E C^{1-\rho}=\exp \left\{(1-\rho)\left[E(c)+\frac{1-\rho}{2} \sigma_{c}^{2}\right]\right\}$, Equation (3.6) ultimately depends only on the second moments of consumption and the exchange rate. To derive these second moments, we rewrite the equations which give the closed-form solution to consumption and the exchange rate in log terms as:

$$
\begin{gathered}
s-E(s)=m-m^{*} \\
c-E(c)=\frac{1}{\rho} m \\
c^{*}-E\left(c^{*}\right)=\frac{1}{\rho}\left[n m+(1-n) m^{*}\right]
\end{gathered}
$$

where small-case letters denote logarithms. The expected utility of the foreign household can be derived in the same way.

We simplify the exposition first and focus on a special case where $\rho=1$, then give the result for the general case where $\rho>1$. When $\rho=1$, the expected labor supplies for

\footnotetext{
${ }^{11}$ Obstfeld and Rogoff $(1998,2002)$ argue that the utility of real balances is small enough to be neglected.
} 
both countries are constant, ${ }^{12} E L=E L^{*}=\frac{1-\alpha}{\eta \hat{\lambda}}$. Thus, the expected utility for the home country only depends on the mean of log consumption, the variance of log consumption has no impact on the expected utility of households.

$$
E U=E c-\frac{1-\alpha}{\hat{\lambda}}
$$

From the money demand function $c=\ln \chi+m-p$ and the assumption $E m=0$, we may find that, when $\rho=1$, the expected utility for home country is fully determined by the expected log price level.

$$
E U=-\ln \chi-\frac{1-\alpha}{\hat{\lambda}}-E p
$$

Expected utility for the foreign country can be derived in the same way, $E U^{*}=-\ln \chi-$ $\frac{1-\alpha}{\hat{\lambda}}-E p^{*}$. From Appendix B, we have

$$
\begin{gathered}
E p=\ln \hat{\lambda} \eta^{1-\alpha}+\frac{(1-\alpha)^{2}}{2}\left(\sigma_{u}^{2}+\sigma_{z}^{2}\right)+\frac{\alpha^{2}}{2} \sigma_{q}^{2} \\
E p^{*}=\ln \hat{\lambda} \eta^{1-\alpha}+\frac{(1-\alpha)^{2}}{2}\left(\sigma_{u}^{2}+\sigma_{z}^{2}\right)+\frac{\alpha^{2}}{2} \sigma_{q}^{2}+(1-n) \alpha \sigma_{u}^{2}
\end{gathered}
$$

It is straightforward to show that $E p<E p^{*}$, and

$$
E U-E U^{*}=(1-n) \alpha \sigma_{u}^{2}>0
$$

Equation (3.14) implies that US households will have higher welfare than those in the rest of the world. Since the only departure from symmetry in the model is the feature that oil prices are set in US dollars, and the fact that this induces asymmetric trade pricing, then this must capture the utility gain to the US from its position as providing a world reference currency for international trade.

The argument extends in a straightforward manner to the case $\rho>1$. In that case, as shown in Appendix $\mathrm{C}$, to prove $E U>E U^{*}$ is equivalent to proving $E C^{(1-\rho)}<E C^{*(1-\rho)}$. Since $\rho>1$ and $E C^{1-\rho}=\exp \left\{(1-\rho)\left[E(c)+\frac{1-\rho}{2} \sigma_{c}^{2}\right]\right\}$, we may define $\Delta E U=(E c+$ $\left.\frac{1-\rho}{2} \sigma_{c}^{2}\right)-\left(E c^{*}+\frac{1-\rho}{2} \sigma_{c^{*}}^{2}\right)$, Appendix $\mathrm{C}$ shows that :

$$
\Delta E U=\frac{n(1-n)(\rho-1)+(1-n) \alpha}{\rho} \sigma_{u}^{2}>0
$$

It follows then that we may state:

\footnotetext{
${ }^{12}$ In the special case where $\rho=1, \Gamma=1$.
} 
Proposition 2 With a dollar standard in international goods pricing, $E U>E U^{*}$ (households in the home country have higher welfare than those in the foreign country).

Proof: See Appendix C.

The intuitive mechanism through which US households gain, relative to those in the rest of the world, is through differences in price levels. While nominal prices are pre-set, the level at which they are set depends on the distribution of marginal cost and consumption, and the stochastic environment induced by the configuration of price-setting itself. Since oil is invoiced in US dollars, the foreign country's marginal cost is relatively more sensitive to exchange rate volatility. This leads to a higher pre-set nominal price of foreign goods. Then, as shown in Equations 3.12 and 3.13, the foreign country has a higher log CPI price. The difference between the expected home and foreign price level is given by $(1-n) \alpha \sigma_{u}^{2}$. So the higher is $\alpha$, the share of oil in the production, the higher is the expected price level difference.

Given the money demand function, a higher expected price level translates into a lower mean of $\log$ consumption. In the special case where $\rho=1$, we have that a) employment is constant, and b) expected utility depends only on the mean, and not the variance, of $\log$ consumption. Hence, expected utility of households, conditional on a given monetary policy, is negatively related to the nominal price level. Since $E p^{*}>E p$, the foreign country is worse off than the home country.

When $\rho>1$, both the mean and variance of $\log$ consumption will affect the expected utility. As shown in Appendix C, the variance of home log consumption is higher than that of the foreign country. Nevertheless, the mean of log consumption is still lower in the foreign country, for the same reason explained above. And this effect dominates the difference in variance of $\log$ consumption. So home households still have a higher welfare then foreign households.

\subsection{Welfare gains from a reference currency}

Qualitatively, we have shown that the US household gains from the role of the US dollar as the international reference currency for trade pricing. But how large can these gains be? As shown in Appendix D, expressions (3.15) above can be interpreted as the fraction of average consumption that the US household would be willing to forgo in order to keep the 
US dollar as the reference currency. Thus, by calibrating the right hand side of (3.15) we can get a measure of the welfare gain to a reference currency, in real terms. ${ }^{13}$

The calibration requires a choice of parameter values for $\rho$, the coefficient of relative risk aversion, $\sigma_{u}^{2}$, the variance of money shocks, $n$, the relative share of the US in world GDP, and $\alpha$, the share of oil (or more generally, primary commodities) in consumption (or GDP). As a baseline case, we may take $\rho=1$. To maximize the potential for large welfare effects, we choose $\sigma_{u}^{2}$ so as to reproduce the variance of the quarterly growth rate of the US real effective exchange rate, which is approximately 0.0025 . Were we to calibrate $\sigma_{u}^{2}$ based on the volatility of money (e.g. M1) growth, the welfare gains would be even smaller. We choose $n=0.2$, giving the US a twenty percent share in world GDP. Finally, we choose $\alpha=0.08$. This is much larger than the share of oil in US GDP (around 3 or 4 percent), but is realistic when we interpret $\alpha$ as the share of primary commodities generally, rather than oil in particular.

Figure 1 illustrates the welfare gain, in terms of percentages of permanent consumption. The most striking aspect is that the gain is extremely small. For our baseline case, the welfare gain is only 0.008 percent. At current prices, US consumption is about 8 trillion dollars. This implies that the total welfare gain to the US economy arising from its reference currency role (the dollar standard) is about 0.64 billion dollars.

Figure 1 shows also how the welfare gain depends on $\rho$ and country size, $n$. As $\rho$ increases, the welfare gain rises, although it remains very small in absolute terms. We let country size increase from its baseline value to 0.5. The dependence on country size is non-monotonic. For low value of $\rho$, a rise in $n$ to 0.5 reduces the welfare gain. For higher value of $\rho$, however, a rise in $\mathrm{n}$ raises the welfare gain. The intuition behind this is as follows. For $\rho=1$, the welfare gain is solely a function of the impact of marginal cost variability on the pre-set price of the foreign country good. When $n$ rises, the weight of the foreign good in both countries CPI indices is smaller, and the negative welfare impact of marginal cost variability is smaller. With $\rho>1$, however, there is a secondary impact of the differential pricing on welfare. This arises due to the covariance of discounted demand (captured by the terms $C^{1-\rho}$ - see Technical Appendix) with marginal costs. This covariance

\footnotetext{
${ }^{13} \mathrm{~A}$ notable feature of this welfare expression is that it does not depend on the volatility of the primary commodity price itself, nor the volatility of productivity shocks. This is because both factors effect welfare equally in the home and foreign countries.
} 
Figure 1: Gains to a Reference Currency

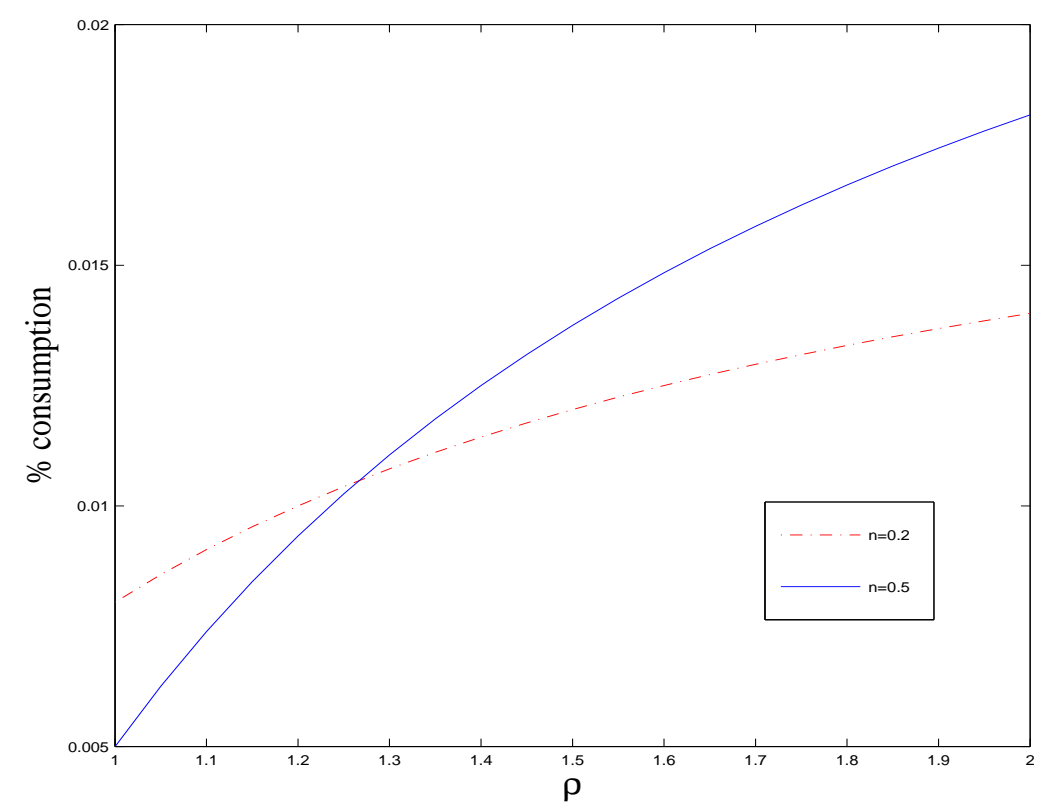

leads to a higher CPI price in the foreign country, (because it experiences exchange rate pass-through of money shocks into consumption, while the home country does not). This effect is maximized at $n=0.5$. Thus, as $\mathrm{n}$ rises towards $n=0.5$, with $\rho>1$, the welfare gains to the international currency will tend to rise. Nevertheless, by any metric, the gains are still exceedingly small.

While the estimates of the welfare benefits of a dollar standard are small in absolute terms, it is worth noting that from a different perspective, the benefits may be sizeable when compared with the benefits of eliminating all monetary policy volatility ${ }^{14}$. In the Technical Appendix, we present a calculation showing that, depending upon the value of $\rho$, and calibrating as in Figure 1, the benefits of a dollar standard (in terms of permanent consumption) may be either less than or greater than the benefits that the home agent

\footnotetext{
${ }^{14}$ Note that this is a somewhat artificial comparison, due to the fact that eliminating monetary policy variability would eliminate the benefits of a dollar standard itself, as is clear from expression 3.15. Nevertheless, as a quantitative statement, it is well known that the cost of uncertainty in such representative agent type models are almost always small, and in relative terms the gains to a dollar standard are not smaller than the usual gains to eliminating consumption risk.
} 
would get from the complete elimination of monetary policy volatility. The higher is $\rho$, the greater will be the benefits of the dollar standard relative to the benefits of eliminating all monetary policy volatility.

\section{The Case with Active Monetary Policies}

So far, we have taken monetary policy as passively determined. But in the presence of nominal price setting, monetary policy may be used to offset the welfare losses from price stickiness. We now extend the model to investigate how the results are affected when monetary policy is set optimally in each country. Now, there exists a sequential game between firms and monetary authorities. The firms choose the currency in which they set their export prices before monetary authorities announce their monetary rules. ${ }^{15}$ Then, given the currency of pricing, each monetary authority chooses its optimal monetary rules in an international non-coordinated game. Note that both firms and monetary authorities make decisions before the state of the world is realized.

It is assumed that the monetary authorities commit to the following form of contingent money rules:

$$
\begin{gathered}
m=a_{0} q+a_{1} z+a_{2} z^{*}+u \\
m^{*}=b_{0} q+b_{1} z+b_{2} z^{*}+u^{*}
\end{gathered}
$$

where $\{\mathrm{a}, \mathrm{b}\}$ are policy parameters and will be discussed later. The term $u$ and $u^{*}$ are the disturbances to money supply, as before.

To characterize the equilibrium, we have to consider the interaction between monetary authorities and firms:

(a) Given firms' currency of pricing, monetary authorities in the home and foreign countries choose the policy parameters $\{a, b\}$ by solving the international monetary Nash game.

$$
\max _{a} E U\left(a, b^{n}\right) \quad \max _{b} E U^{*}\left(a^{n}, b\right)
$$

(b) The optimal policy parameters $\{\mathrm{a}, \mathrm{b}\}$ from Equation (4.3) must support both home and foreign firms's pricing strategies.

\footnotetext{
${ }^{15}$ If we change the timing of the action of firms and monetary authorities and let monetary authorities move first, then monetary authorities can use policy to indirectly choose the currency of pricing of firms, see Devereux, Shi, and Xu (2005b).
} 
To find the equilibrium, we express the expected profit differential of firms' currency of pricing decision as functions of policy parameters $\{a, b\}$. The Technical Appendix gives the expression of $\Omega(a, b)$ and $\Omega^{*}(a, b)$. There exist four possible pricing specification for home and foreign firms. They are $\left\{s_{h}, s_{f}\right\}=\{P C P, P C P\},\{L C P, L C P\},\{L C P, P C P\}$, and $\{P C P, L C P\}$, respectively, where $s_{h}\left(s_{f}\right)$ is the export pricing strategy of home (foreign) firms. The procedure for constructing an equilibrium is to solve for the optimal monetary rules under each of the four possible cases, and then to check whether, given the optimal monetary rules, the firms' optimal pricing decision is consistent with the stated pricing policy as an equilibrium, in each case. For simplicity, we focus on the case where $\rho=1$, but the results also hold in the more general case where $\rho>1 .^{16}$

In the Technical Appendix, we show that $\left\{s_{h}, s_{f}\right\}=\{L C P, L C P\}$ and $\{L C P, P C P\}$ will not be feasible equilibria. The reason is that all home firms will wish to follow PCP under all circumstances. Hence, there is no equilibrium under which home firms follow LCP. ${ }^{17} \mathrm{In}$ Table 3 , therefore, we focus only on the two cases $\{P C P, P C P\}$ and $\{P C P, L C P\}$. The Table gives the optimal monetary policy parameters and the expected profit differential for the two possible pricing strategies when $\rho=1 .{ }^{18}$

From Table 3, we can see that the optimal monetary policy response to the oil price shock is the same for each of the two cases. Since the oil price shock is a common shock to both countries, the optimal monetary policy requires both home and foreign monetary authorities to respond in the same way. To fully eliminate the effect of the oil price shock on firms' marginal cost, for a one percent increase in the oil price, the nominal wage should decrease by $\frac{\alpha}{1-\alpha}$, so the monetary authorities should reduce the money supply by $\frac{\alpha}{1-\alpha}$ percent.

To see how an equilibrium can be derived from the results of the Table, we focus on the gains to the individual firm $\Omega(a, b)$ and $\Omega^{*}(a, b)$ in each conjectured configuration

\footnotetext{
${ }^{16}$ The value of the risk aversion parameter $\rho$ only affects the welfare level and has no impact on the currency of pricing decisions for firms and the equilibrium of the game. Specifically, in the symmetric pricing specification, the optimal monetary rules are independent of the parameter $\rho$.

${ }^{17}$ Specifically, when $\left\{s_{h}, s_{f}\right\}=\{L C P, L C P\}, a_{0}=-\frac{\alpha}{1-\alpha}, a_{1}=n, a_{2}=1-n, b_{0}=-\frac{\alpha}{1-\alpha}, b_{1}=n$, $b_{2}=1-n$. Hence, given $\{a, b\}, \Omega(a, b)>0$ and $\Omega^{*}(a, b)<0$. So it is not a possible equilibrium. When $\left\{s_{h}, s_{f}\right\}=\{L C P, P C P\}, a_{0}=-\frac{\alpha}{1-\alpha}, a_{1}=\frac{1-n \alpha}{1-\alpha}, a_{2}=\frac{-(1-n) \alpha}{1-\alpha}, b_{0}=-\frac{\alpha}{1-\alpha}, b_{1}=\frac{n(1-2 \alpha)+\alpha}{1-\alpha}$, $b_{2}=\frac{(1-n)(1-2 \alpha)}{1-\alpha}$. This implies that $\Omega(a, b)>0$, so $\{L C P, P C P\}$ is not a feasible equilibrium either.

${ }^{18}$ The optimal parameters for the more general case where $\rho>1$ depends on $\rho$, but they give the same intuition.
} 
$\{P C P, P C P\}$ and $\{P C P, L C P\}$. If either firm has an incentive to deviate from the pricing strategy conjectured, then obviously that strategy is not an equilibrium.

From the Table, it is clear that under either case, it is optimal for the home country firm to continue to follow PCP. Even without oil as an input, the home firm would no longer be indifferent between PCP and LCP pricing (as it would without optimal monetary policy), because optimal monetary policy leads to a higher variance of the exchange rate that is not associated with a higher covariance of marginal costs and the exchange rate, so from (2.21), the optimal monetary policy tilts the calculation towards PCP.

For the foreign firm, the calculation is different. If the variance of productivity shocks is high enough, Table 3 indicates that again, the foreign firm will choose PCP, (so the $\{P C P, L C P\}$ configuration cannot be an equilibrium). In particular, if

$$
\frac{\sigma_{z}^{2}}{\sigma_{u}^{2}}>\frac{\alpha}{n^{2}(1-\alpha)^{2}}
$$

then the only equilibrium will be $\{P C P, P C P\}$, since the foreign firm will choose $P C P$ in all cases. ${ }^{19}$ If on the other hand,

$$
\frac{\sigma_{z}^{2}}{\sigma_{u}^{2}}<\frac{\alpha}{1-2 \alpha}
$$

then $\{P C P, L C P\}$ is the only equilibrium, since the foreign firm will choose LCP in all cases. Note from these two conditions that the oil input is necessary to sustain the $\{P C P, L C P\}$ equilibrium since if $\alpha=0$, then all foreign firms will follow PCP, and the only equilibrium is $\{P C P, P C P\}$.

On the other hand, if

$$
\frac{\alpha}{1-2 \alpha}<\frac{\sigma_{z}^{2}}{\sigma_{u}^{2}}<\frac{\alpha}{n^{2}(1-\alpha)^{2}}
$$

then there are two equilibria, since it can be established from Table 3 that the foreign firm would not wish to deviate either from $\{P C P, P C P\}$ or $\{P C P, L C P\}$.

We may summarize the above arguments in the following proposition.

Proposition 3 If $\frac{\sigma_{z}^{2}}{\sigma_{u}^{2}} \geq \frac{\alpha}{n^{2}(1-\alpha)^{2}}$, there is a unique equilibrium for the game between firms and monetary authorities that all firms follow PCP; If $\frac{\alpha}{1-2 \alpha}<\frac{\sigma_{z}^{2}}{\sigma_{u}^{2}}<\frac{\alpha}{n^{2}(1-\alpha)^{2}}$, there will be two equilibria: one is the case that all firms follow PCP, the other is the case that all home firms follow PCP and all foreign firms follow LCP. The latter case represents a dollar

\footnotetext{
${ }^{19}$ For any reasonable values of parameters, we always have $\frac{\alpha}{1-2 \alpha}<\frac{\alpha}{n^{2}(1-\alpha)^{2}}$.
} 
standard. If $\frac{\sigma_{z}^{2}}{\sigma_{u}^{2}}<\frac{\alpha}{1-2 \alpha}$, there exists a unique equilibrium that all home firms follow PCP and all foreign firms follow LCP, that also represents a dollar standard.

Proposition 3 implies that the equilibrium depends on the relative size of productivity shocks. If productivity shocks are relatively small, then a dollar standard can be an equilibrium, so long as oil is an input into production. But if there are large productivity shocks, then the variance of the optimal exchange rate increases. This encourages both home firms and foreign firms to follow PCP. Given the size of shocks, an increase in $\alpha$ will increase the possibility of a dollar standard in international goods pricing. An increase in $n$ will reduce the distance between two threshold values of $\frac{\sigma_{z}^{2}}{\sigma_{u}^{2}}$, which in turn lowers the possibility of multiple equilibria.

Will US still gain from a dollar standard in this case? Given the difference between expected utility of the home household and the foreign household under a dollar standard (see Appendix E for detailed derivation) ${ }^{20}$

$$
E U-E U^{*}=(1-n) \alpha \sigma_{u}^{2}-n^{2}(1-n)(1-\alpha)^{2} \sigma_{z}^{2},
$$

We find that the condition for a dollar standard as a possible equilibrium, $\frac{\sigma_{z}^{2}}{\sigma_{u}^{2}}<\frac{\alpha}{n^{2}(1-\alpha)^{2}}$, ensures that $E U>E U^{*}$. Thus, we have the following proposition.

Proposition 4 In an environment with active monetary policies, the households in the U.S. are better off than those in the rest of the world when there is a dollar standard.

How does the revised welfare estimate affect the gains to a reference currency? From Equation (4.6), we see that the gains are in fact reduced. Intuitively, this is because, when monetary policy is employed optimally, the foreign country can use its monetary rule to generate a fully efficient response of consumption to domestic and foreign productivity shocks, since there is positive exchange rate pass-through into the foreign country, and the expenditure switching mechanism works efficiently in the foreign economy. But the home country cannot do this, because there is no exchange rate pass-through into the home

\footnotetext{
${ }^{20}$ The welfare of households in both countries are only a function of the variance of productivity shocks and monetary shocks, as the optimal monetary policy fully eliminates the effect of oil price shock (common shock) on the welfare.
} 
country at all. ${ }^{21}$ As a result, the welfare benefits to the reference currency country are lower, in the presence of an optimal monetary policy response. But it is easy to establish that the reduction in the welfare gain is of second order. For instance, for a value of $\sigma_{z}^{2}=0.001$ (roughly the variance in the Solow Residual for the US economy), using the same baseline calibration as in Section 3.4, the welfare gain to the reference currency goes from 0.008 percent to 0.0053 percent.

\section{Conclusion}

This paper constructs a model of the US dollar as an international trade currency for trade in final goods, and shows that this is directly linked to the role of the dollar as an invoicing currency in primary commodities. When the currency of export pricing is itself endogenous and primary commodities are required for production, the practice of US dollar pricing of export goods follows as a natural implication of dollar invoicing of primary commodities, both for US exporters and for foreign firms exporting to the US. Hence the convention of dollar invoicing of primary commodities leads naturally to the asymmetric pattern in the currency of price setting for trade in final goods. When the model is extended to allow for an optimal monetary policy followed in each country, a dollar standard can still be an equilibrium, but this depends critically on the relative sizes of external shocks.

Our model implies that the US consumer gains from the use of the dollar as an invoicing currency. Using a simple formula derived from our model, we may calculate the magnitude of the welfare benefit that the US obtains from its position as a reference currency. Nevertheless, we find that the gains to the representative US household are extremely small.

The model takes the world price of primary commodities as exogenous. An interesting extension of the model would be to incorporate the decision making of primary commodity producers into the analysis. We leave this for future research.

\footnotetext{
${ }^{21}$ This welfare cost from having dollar as the invoicing currency is mentioned in Devereux, Shi and Xu (2007) and Goldberg and Tille (2008b). In this paper, however, these costs are offset by the direct welfare gains from having a more stable marginal cost, and a lower mean price level.
} 


\section{References}

[1] Bacchetta, Philippe and Eric van Wincoop (2005), "A Theory of the Currency Denomination of International Trade," Journal of International Economics, 67(2) 295-319.

[2] Bamberg, James (2000), "British Petroleum and Global Oil, 1950-1975, The Challenge of Nationalism" Cambridge University Press.

[3] Bekx, P., 1998. The implications of the introduction of the Euro for non-EU countries. Euro Papers No. 26, European Commission.

[4] Bodenstein, Martin, Christopher Erceg, and Luca Guerrieri (2007), "Oil Shocks and External Adjustment," International Finance Discussion Papers 897, Board of Governors of the Federal Reserve System.

[5] Cook, David and Michael B. Devereux, 2006, "External Currency Pricing and the East Asian Crisis", Journal of International Economics, 69(1), 37-63.

[6] Devereux, Michael B., and Charles Engel (2003), "Monetary Policy in the Open Economy Revisited: Price Setting and Exchange Rate Flexibility," The Review of Economic Studies 70(4), 765-783.

[7] Devereux, Michael B., Charles Engel, and Peter Storgaard (2004), "Endogenous Exchange Rate Pass-through When Nominal Price are Set in Advance," Journal of International Economics 63(2), 263-291.

[8] Devereux, Michael B., Kang Shi and Juanyi Xu (2005a), "Oil Currency and the Dollar Standard," Mimeo, UBC Department of Economics.

[9] Devereux, Michael B., Kang Shi and Juanyi Xu (2005b), "Friedman Redux : Restricting Monetary Policy Rules to Support Flexible Exchange Rates," Economics Letters 87(3), 291-299.

[10] Devereux, Michael B., Kang Shi and Juanyi Xu (2007), "The Global Monetary Policy under a Dollar Standard," Journal of International Economics 71(1), 113-132.

[11] Devereux, Michael B. and Shouyong Shi, "Vehicle Currency,", Federal Reserve Bank of Dallas Globalization and Monetary Policy Institute Working Paper No. 10.

[12] Elekdag, Selim, Douglas Laxton, René Lalonde, Dirk Muir, and Paolo Pesenti (2008), "Oil Price Movements and the Global Economy: A Model-Based Assessment," IMF Staff Papers $55(2), 297-311$ 
[13] Engel, Charles (1999), "Accounting for U.S. Real Exchange Rate Changes," Journal of Political Economy 107, 507-538.

[14] Frankel, Jeffrey A., David C. Parsley, and Shang-Jin Wei (2005), "Slow Passthrough Around the World: A New Import for Developing Countries?", NBER Working Papers 11199.

[15] Friberg, Richard (1998), "In Which Currency Should Exporters Set Their Prices?" Journal of International Economics 45(1), 59-76.

[16] Giovannini, Alberto (1988), "Exchange Rates and Traded Goods Prices," Journal of International Economics 24(1), 45-68.

[17] Goldberg, Linda, and Cedric Tille (2008a), "Vehicle Currency Use in International Trade," Journal of International Economics 76(2), 177-192.

[18] Goldberg, Linda, and Cedric Tille (2008b), "Macroeconomic Interdependence and the International Role of the Dollar," CEPR Discussion Papers 6704.

[19] Gopinath, Gita, and Roberto Rigobon (2008), "Sticky Borders," The Quarterly Journal of Economics 123(2), 531-575.

[20] Hamilton, James D. (1983), "Oil and the Macroeconomy Since World War II," Journal of Political Economy 91(2), 228-248.

[21] Hamilton, James D. (1985), "Historical Causes of Postwar Oil Shocks and Recessions," Energy Journal 6, 97-116.

[22] Hartmann, Philipp (1998), "The Currency Denomination of World Trade after European Monetary Union," Journal of the Japanese and International Economies 12, 424-454.

[23] Krugman, Paul R. (1980), "Vehicle Currencies and the Structure of International Exchange," Journal of Money, Credit and Banking 12(3), 513-526.

[24] Krugman, Paul R. (1983), "Oil and the Dollar," in Economic Interdependence Under Flexible Exchange Rates, eds by J. Bhandari and B. Putnam, 179-190. Cambridge: Massachusetts Institute of Technology,

[25] Leduc, Sylvain, and Keith Sill (2007), "Monetary Policy, Oil Shocks, and TFP: Accounting for the Decline in U.S. Volatility," Review of Economic Dynamics 10(4), 595-614

[26] McKinnon, Ronald (2001), "The International Dollar Standard and the Sustainability of US Current Account Deficits," Brookings Papers on Economic Activity 32(1), 227-241. 
[27] McKinnon, Ronald (2002), "The Euro versus the Dollar: Resolving a Historical Puzzle," Journal of Policy Modeling 24(4), 355-359.

[28] McKinnon, Ronald and Gunther Schnabl (2004), "The East Asian Dollar Standard, Fear of Floating, and Original Sin," Review of Development Economics 8(3), 331-360.

[29] Mork, Knut A., and Robert E. Hall (1980), "Energy Prices, Inflation, and Recession," Energy Journal 15, 31-63.

[30] Novy, Dennis (2006), "Hedge Your Costs: Exchange Rate Risk and Endogenous Currency Invoicing," University of Warwich Economic Research Paper 765.

[31] Obstfeld, Maurice, and Kenneth Rogoff (1998), "Risk and Exchange Rates," NBER Working Papers 6694.

[32] Obstfeld, Maurice, and Kenneth Rogoff (2000), "New Direction for Stochastic Open economy Models," Journal of International Economics 50(1), 117-157.

[33] Obstfeld, Maurice, and Kenneth Rogoff (2002), "Global Implication of Self-Oriented National Monetary Rules," Quarterly Journal of Economics 117(2), 503-535.

[34] Portes, Richard and Helene Rey (1998), "The Emergence of the Euro as an International Currency," Economic Policy 26, 305-343.

[35] Rey, Helene (2001), "International Trade and Currency Exchange", Review of Economic Studies 68 (2), 443-464.

[36] Tavlas, G.S., 1997. International use of the US dollar: an optimum currency area perspective. The World Economy 20, 730-747. 
Table 1: The Currency Denomination of Commodity Goods Prices ${ }^{a}$

\begin{tabular}{|c|c|c|c|}
\hline \multicolumn{4}{|c|}{ Rogers International Commodities Index } \\
\hline Commodity & Exchange & Currency & Weight in the Index \\
\hline \multirow[t]{2}{*}{ Crude Oil } & NYMEX & USD & $21 \%$ \\
\hline & ICE Brent Future & USD & $14 \%$ \\
\hline Heating Oil & NYMEX & USD & $1.8 \%$ \\
\hline RBOB Gasoline & NYMEX & USD & $3 \%$ \\
\hline Natural Gas & NYMEX & USD & $3 \%$ \\
\hline Aluminum & LME & USD & $4 \%$ \\
\hline Copper & LME & USD & $4 \%$ \\
\hline Zinc & LME & USD & $2.00 \%$ \\
\hline Lead & LME & USD & $2.00 \%$ \\
\hline Silver & COMEX & USD & $2.00 \%$ \\
\hline Gold & COMEX & USD & $3.00 \%$ \\
\hline Platinum & COMEX & USD & $1.80 \%$ \\
\hline Lumber & $\mathrm{CME}$ & USD & $1.00 \%$ \\
\hline Corn & CBOT & USD & $4.75 \%$ \\
\hline Cotton & NYCE & USD & $4.20 \%$ \\
\hline Soybeans & CBOT & USD & $3.35 \%$ \\
\hline Azuki Beans & TGE & JPY & $0.15 \%$ \\
\hline Greasy Wool & SFE & AUS & $0.10 \%$ \\
\hline Rubber & TOCOM & JPY & $1.00 \%$ \\
\hline Barley & WCE & $\mathrm{CAD}$ & $0.10 \%$ \\
\hline Canola & WCE & $\mathrm{CAD}$ & $0.67 \%$ \\
\hline \multicolumn{4}{|c|}{ UNCTAD Commodity Price Series ${ }^{b}$} \\
\hline \multicolumn{4}{|c|}{ Commodity Goods priced in currencies other than US Dollars } \\
\hline Commodity & & & Currency \\
\hline Cocoa & Average of daily $\mathrm{p}$ & NDON, 3 months futures & SDR \\
\hline Rubber & In Bales & OB Singapore & Singapore Dollar \\
\hline Copper & London Metal & e A, Cash Settlement & Sterling Pound \\
\hline Lead & London M & Cash Settlement & Sterling Pound \\
\hline Tin & Kuala & , Ex-Smelter & Malaysian Dollar \\
\hline
\end{tabular}


Table 2: US Dollar Use in Invoicing Imports and Exports for Selected Countries (\%) ${ }^{c}$

\begin{tabular}{lccc}
\hline \hline Country & Observation year & $\begin{array}{c}\text { US\$ share } \\
\text { in Export Invoicing }\end{array}$ & $\begin{array}{c}\text { US\$ share } \\
\text { in Import Invoicing }\end{array}$ \\
\hline US & $1992-1996$ & $98 \%$ & $92.8 \%$ \\
& 1995 & $92 \%$ & $80.7 \%$ \\
Japan & 2003 & $99.8 \%$ & $92.8 \%$ \\
& 1995 & $52.2 \%$ & $70.2 \%$ \\
Korea & 2001 & $52.4 \%$ & $70.7 \%$ \\
\multirow{2}{*}{ Australia } & 1995 & $88.1 \%$ & - \\
& 2001 & $84.9 \%$ & $82.2 \%$ \\
\multirow{3}{*}{ United Kingdom } & 2002 & $67.9 \%$ & $50.1 \%$ \\
& 2006 & $75.3 \%$ & $51.4 \%$ \\
& 2007 & $74.3 \%$ & $52 \%$ \\
\hline \hline
\end{tabular}

${ }^{c}$ Source: The data for the US are from Tavlas (1997), Bekx (1998), and Goldberg and Tille (2008). The data for Korea and Japan are from Bekx (1998), Cook and Devereux (2006), and Goldberg and Tille (2008). Australia data are from Australian Bureau of Statistics and Goldberg and Tille (2008). UK data are from United Kingdom HM Customs and Excise and Goldberg and Tille (2008).

Table 3: The Optimal Monetary Parameters and Expected Profit Differential

\begin{tabular}{ccc}
\hline \hline & $(\mathrm{PCP}, \mathrm{PCP})$ & $(\mathrm{PCP}, \mathrm{LCP})$ \\
\hline & Optimal Monetary Policy Parameters \\
\hline$a_{0}$ & $-\frac{\alpha}{1-\alpha}$ & $-\frac{\alpha}{1-\alpha}$ \\
$a_{1}$ & 1 & $\mathrm{n}$ \\
$a_{2}$ & 0 & $1-\mathrm{n}$ \\
$b_{0}$ & $-\frac{\alpha}{1-\alpha}$ & $-\frac{\alpha}{1-\alpha}$ \\
$b_{1}$ & 0 & $n \alpha$ \\
$b_{2}$ & 1 & $1-n \alpha$ \\
\hline \multicolumn{4}{c}{ Expected Profit Differential given optimal $\{\mathrm{a}, \mathrm{b}\}$} \\
\hline$\Omega^{*}(a, b)$ & $\sigma_{z}^{2}+\alpha \sigma_{u}^{2}>0$ & $n(2-n)(1-\alpha)^{2} \sigma_{z}^{2}+\alpha \sigma_{u}^{2}>0$ \\
Equilibrium Condition & $(1-2 \alpha) \sigma_{z}^{2}-\alpha \sigma_{u}^{2}$ & $n^{2}(1-\alpha)^{2} \sigma_{z}^{2}-\alpha \sigma_{u}^{2}$ \\
\hline \hline
\end{tabular}




\section{Appendix}

\section{A Proof of Proposition 1}

Firstly, taking logs of Equations (2.9), (2.13), and (2.14) an using the fact the covariance terms between $\left\{u, u^{*}, z, z^{*}, q\right\}$ are all zero, we have:

$$
\begin{gathered}
\frac{1}{2} \sigma_{s}^{2}=\frac{1}{2}\left(\sigma_{u}^{2}+\sigma_{u^{*}}^{2}\right) \\
\operatorname{cov}(m c, s)=(1-\alpha) \sigma_{u}^{2} \quad \operatorname{cov}\left(m c^{*}, s\right)=-(1-\alpha) \sigma_{u^{*}}^{2}-\alpha\left(\sigma_{u}^{2}+\sigma_{u^{*}}^{2}\right)
\end{gathered}
$$

So from Equation (2.21) and (2.22), we can get the expected profit differentials $\Omega$ and $\Omega^{*}$

$\Omega=\frac{1}{2} \sigma_{s}^{2}-\operatorname{cov}(m c, s)=\left(\alpha-\frac{1}{2}\right) \sigma_{u}^{2}+\frac{1}{2} \sigma_{u^{*}}^{2} \quad \Omega^{*}=\frac{1}{2} \sigma_{s}^{2}+\operatorname{cov}\left(m c^{*}, s\right)=\left(\frac{1}{2}-\alpha\right) \sigma_{u}^{2}-\frac{1}{2} \sigma_{u^{*}}^{2}$

If $\sigma_{u}^{2}=\sigma_{u^{*}}^{2}$, then we have

$$
\Omega=\frac{1}{2} \sigma_{s}^{2}-\operatorname{cov}(m c, s)=\alpha \sigma_{u}^{2}>0 \quad \Omega^{*}=\frac{1}{2} \sigma_{s}^{2}+\operatorname{cov}\left(m c^{*}, s\right)=-\alpha \sigma_{u}^{2}<0
$$

If $\sigma_{u}^{2} \neq \sigma_{u^{*}}^{2}$, the condition for the above result to hold becomes

$$
\frac{\sigma_{u}^{2}}{\sigma_{u^{*}}^{2}}<\frac{1}{1-2 \alpha}
$$

QED.

\section{B Welfare Comparison for the Special Case $\rho=1$}

From the price index and pricing equations (see Technical Appendix), we have

$$
P=P_{h h^{n}} P_{f h}^{1-n}=\hat{\lambda} E[M C]^{n} E\left[M C^{*} S\right]^{1-n}
$$

Using the marginal cost functions (2.13) and (2.14), and the optimality conditions (2.7)(2.9), we can get

$P=\hat{\lambda}\left(\frac{\eta}{\chi}\right)^{1-\alpha} E\left[\left(\frac{M}{\theta}\right)^{1-\alpha} Q^{\alpha}\right]^{n} E\left[\left(\frac{M^{*}}{\theta^{*}}\right)^{1-\alpha} Q^{\alpha} S^{1-\alpha}\right]^{1-n}=\hat{\lambda}\left(\frac{\eta}{\chi}\right)^{1-\alpha} E\left[\left(\frac{M}{\theta}\right)^{1-\alpha} Q^{\alpha}\right]^{n} E\left[\left(\frac{M}{\theta^{*}}\right)^{1-\alpha} Q^{\alpha}\right]^{1-n}$

Using the log normal property of these shocks and taking log, we have

$$
E p=p=\ln \hat{\lambda}\left(\frac{\eta}{\chi}\right)^{1-\alpha}+\frac{(1-\alpha)^{2}}{2} \sigma_{u}^{2}+\frac{(1-\alpha)^{2}}{2} \sigma_{z}^{2}+\frac{\alpha^{2}}{2} \sigma_{q}^{2}
$$


The price index in foreign country is given by

$$
P^{*}=\left[\frac{P_{h f}}{S}\right]^{n}\left(P_{f f}\right)^{1-n}
$$

We denote $P^{*}=\frac{Z}{S^{n}}$, where

$Z=P_{h f}^{n}\left(P_{f f}\right)^{1-n}=\hat{\lambda} E[M C]^{n} E\left[M C^{*}\right]^{1-n}=\hat{\lambda}\left(\frac{\eta}{\chi}\right)^{1-\alpha} E\left[\left(\frac{M}{\theta}\right)^{1-\alpha} Q^{\alpha}\right]^{n} E\left[\left(\frac{M^{*}}{\theta^{*}}\right)^{1-\alpha} Q^{\alpha} S^{-\alpha}\right]^{1-n}$

Since $p^{*}=\ln Z-n \ln S$ and $E \ln S=0$ when $\Gamma=1$, we have

$$
E p^{*}=\ln Z=\ln \hat{\lambda}\left(\frac{\eta}{\chi}\right)^{1-\alpha}+\frac{(1-\alpha)^{2}}{2} \sigma_{u}^{2}+\frac{(1-\alpha)^{2}}{2} \sigma_{z}^{2}+\frac{\alpha^{2}}{2} \sigma_{q}^{2}+(1-n) \alpha \sigma_{u}^{2}
$$

So that, we have

$$
E p<E p^{*}, \quad E U>E U^{*}
$$

QED.

\section{Proof of Proposition 2}

When $\rho>1$, from Devereux, Shi, and Xu (2007), using $\Gamma=\frac{E C^{(1-\rho)}}{E C^{*(1-\rho)}}$, we can simplify $E U$ and $E U^{*}$ as :

$$
\begin{aligned}
E U & =\frac{\lambda-(\lambda-1)(1-\rho)}{(1-\rho) \lambda} E C^{(1-\rho)} \\
E U^{*} & =\frac{\lambda-(\lambda-1)(1-\rho)}{(1-\rho) \lambda} E C^{*(1-\rho)}
\end{aligned}
$$

Since $\frac{\lambda-(\lambda-1)(1-\rho)}{(1-\rho) \lambda}$ is negative, to prove $E U>E U^{*}$ is equivalent to proving $\Gamma<1$ or $E C^{(1-\rho)}<E C^{*(1-\rho)}$. Since $\rho>1$, we only need to show the following condition holds

$$
E c+\frac{1-\rho}{2} \sigma_{c}^{2}>E c^{*}+\frac{1-\rho}{2} \sigma_{c^{*}}^{2}
$$

For notational convenience, we define

$$
\Delta E U=\left(E c+\frac{1-\rho}{2} \sigma_{c}^{2}\right)-\left(E c^{*}+\frac{1-\rho}{2} \sigma_{c^{*}}^{2}\right)=\left(E c-E c^{*}\right)-\frac{1-\rho}{2}\left(\sigma_{c^{*}}^{2}-\sigma_{c}^{2}\right)
$$

From the Equation (3.8) and (3.9), we have

$$
\sigma_{c}^{2}=\frac{1}{\rho^{2}} \sigma_{u}^{2} \quad \sigma_{c^{*}}^{2}=\frac{1-2 n(1-n)}{\rho^{2}} \sigma_{u}^{2}
$$


From home and foreign money demand functions, we have

$$
E c-E c^{*}=\frac{1}{\rho}\left(E p^{*}-E p\right)
$$

From the pricing equation and price index, we have

$$
\begin{gathered}
P=\hat{\lambda}\left(\frac{\eta}{\chi}\right)^{1-\alpha} \frac{E\left[\left(\frac{M}{\theta}\right)^{1-\alpha} Q^{\alpha} C^{1-\rho}\right]^{n} E\left[\left(\frac{M^{*}}{\theta^{*}}\right)^{1-\alpha} Q^{\alpha} S^{1-\alpha} C^{1-\rho}\right]^{1-n}}{E\left[C^{1-\rho}\right]} \\
P^{*}=S^{-n} \hat{\lambda}\left(\frac{\eta}{\chi}\right)^{1-\alpha} \frac{E\left[\left(\frac{M}{\theta}\right)^{1-\alpha} Q^{\alpha} C^{* 1-\rho}\right]^{n} E\left[\left(\frac{M^{*}}{\theta^{*}}\right)^{1-\alpha} Q^{\alpha} S^{-\alpha} C^{* 1-\rho}\right]^{1-n}}{E\left[C^{* 1-\rho}\right]}
\end{gathered}
$$

Using the log normal distribution property of underline shocks, we can derive

$$
\begin{aligned}
E p= & \ln \hat{\lambda}\left(\frac{\eta}{\chi}\right)^{1-\alpha}+\frac{\left(\frac{1}{\rho}-\alpha\right)^{2}}{2} \sigma_{u}^{2}+\frac{(1-\alpha)^{2}}{2} \sigma_{z}^{2}+\frac{\alpha^{2}}{2} \sigma_{q}^{2}-\frac{\left(\frac{1}{\rho}-1\right)^{2}}{2} \sigma_{u}^{2} \\
& +(1-\alpha)(1-n) \ln \Gamma \\
E p^{*}= & \ln \hat{\lambda}\left(\frac{\eta}{\chi}\right)^{1-\alpha}+\frac{\left(\frac{1}{\rho}-\alpha\right)^{2}}{2} \sigma_{u}^{2}+\frac{(1-\alpha)^{2}}{2} \sigma_{z}^{2}+\frac{\alpha^{2}}{2} \sigma_{q}^{2}-\frac{\left(\frac{1}{\rho}-1\right)^{2}}{2} \sigma_{u}^{2} \\
& +\left[\frac{2 n(1-n)(\rho-1)+(1-n) \alpha}{\rho}\right] \sigma_{u}^{2}+[-\alpha(1-n)-n] \ln \Gamma
\end{aligned}
$$

So we have

$$
E c-E c^{*}=\frac{1}{\rho}\left(E p^{*}-E p\right)=\frac{1}{\rho^{2}}[2 n(1-n)(\rho-1)+(1-n) \alpha] \sigma_{u}^{2}-\frac{1}{\rho} \ln \Gamma
$$

From Equations (C.5) and (C.11), we have

$$
\Delta E U=\frac{n(1-n)(\rho-1)+(1-n) \alpha}{\rho^{2}} \sigma_{u}^{2}-\frac{1}{\rho} \ln \Gamma
$$

We can express $\ln \Gamma$ in terms of $\Delta E U$. Note that

$\ln \Gamma=\ln E C^{(1-\rho)}-\ln E C^{*(1-\rho)}=(1-\rho)\left(E c+\frac{1-\rho}{2} \sigma_{c}^{2}\right)-(1-\rho)\left(E c^{*}+\frac{1-\rho}{2} \sigma_{c^{*}}^{2}\right)=(1-\rho) \Delta E U$

Substituting Equation (C.13) into Equation (C.12), we can have

$$
\Delta E U=\frac{n(1-n)(\rho-1)+(1-n) \alpha}{\rho} \sigma_{u}^{2}>0
$$

Thus, Equation (C.3) holds and $E U>E U^{*}$. QED 


\section{Welfare Gains}

The welfare gains of the US households can be interpreted as the fraction of average consumption that the US household would be willing to forgo in order to keep the US dollar as the reference currency. That is:

$$
E\left[((1+\xi) C)^{1-\rho}\right]=E\left[C^{* 1-\rho}\right]
$$

where $\xi$ is the measure of the welfare difference. Since

$$
\begin{aligned}
E\left[((1+\xi) C)^{1-\rho}\right] & =(1-\xi)^{1-\rho} \exp \left\{(1-\rho)\left[E c+\frac{1-\rho}{2} \sigma_{c}^{2}\right]\right\} \\
E\left[C^{* 1-\rho}\right] & =\exp \left\{(1-\rho)\left[E c^{*}+\frac{1-\rho}{2} \sigma_{c^{*}}^{2}\right]\right\}
\end{aligned}
$$

Taking logs of (D.1), we can get

$$
(1-\rho) \ln (1+\xi)+(1-\rho)\left(E c+\frac{1-\rho}{2} \sigma_{c}^{2}\right)=(1-\rho)\left(E c^{*}+\frac{1-\rho}{2} \sigma_{c^{*}}^{2}\right)
$$

Finally, since $\xi$ is small, using the definition of $\Delta E U$ from Appendix $\mathrm{C}$, we have

$$
\xi \approx \ln (1+\xi)=-\Delta E U
$$

\section{E Derivation of Equation (4.6)}

When $\rho=1$, as shown in Section 3.3, $E U=-\ln \chi-\frac{1-\alpha}{\hat{\lambda}}-E p$ and $E U^{*}=-\ln \chi-\frac{1-\alpha}{\hat{\lambda}}-E p^{*}$. Following the steps as in Appendix C, and using the policy parameters for the asymmetric case $\{\mathrm{PCP}, \mathrm{LCP}\}$ in Table $3^{22}$, we may derive the expected utilities for home and foreign households as:

$$
\begin{gathered}
E U=-\left\{\ln \hat{\lambda}\left(\frac{\eta}{\chi}\right)^{1-\alpha}+n(1-n)(1-\alpha)^{2} \sigma_{z}^{2}+\frac{(1-\alpha)^{2}}{2} \sigma_{u}^{2}\right\} \\
E U^{*}=-\left\{\ln \hat{\lambda}\left(\frac{\eta}{\chi}\right)^{1-\alpha}+n(1-n)^{2}(1-\alpha)^{2} \sigma_{z}^{2}+\frac{n(1-\alpha)^{2}}{2} \sigma_{u}^{2}+\frac{(1-n)\left(1+\alpha^{2}\right)}{2} \sigma_{u}^{2}\right\}
\end{gathered}
$$

This gives the welfare gain for home households:

$$
E U-E U^{*}=-n^{2}(1-n)(1-\alpha)^{2} \sigma_{z}^{2}+(1-n) \alpha \sigma_{u}^{2}
$$

\footnotetext{
${ }^{22}$ The detailed derivation of the expression for the home and foreign utility and the optimal policy parameters $\{a, b\}$ is given in the Technical Appendix.
} 